\title{
Theodoridis Thedoros and Krämer Jürgen (eds.): Spinal injection techniques
}

\author{
Georg Thieme Verlag, Stuttgart, New York, 2009, Various pages with illustrations \\ and tables, Hardcover, Euro (D) 139.95 CHF 232.00, ISBN: 978-3-13-145071-5
}

Pierre Kehr

Received: 28 February 2010 / Accepted: 1 March 2010 / Published online: 12 March 2010

(C) Springer-Verlag 2010

When one as well knows the importance of the infiltrations with a diagnostic aim as with a therapeutic aim, one can only be delighted by the publication of this work. It is indeed about a true atlas of the various spinal infiltrations, creates in famous Institute for Spine Research At the Ruhr University of Bochum.

The work is divided into twelve chapters, gathered in two parts: Chapters 1-4 comprising the basic principles, the elements of the clinical diagnosis, the treatments of the pain and the symptomatic treatments are found in a first part of general information.

Follows then a topographic atlas describing all the infiltrations, since the cervical infiltrations until the lumbar infiltrations (Chapters 7-9). The Chapter 5 that precedes is devoted to the metameric anatomy of the spine and with the conduction of the pain, and Chapter 6 is devoted to the counter-indications.
Then the chapters devoted to the various levels come: there still are initially pointed out basic anatomo-physiological concepts, then the various infiltrations described clearly with splendid diagrams and photographs, with precise centimetric information of the cutaneous reference landmarks.

The work ends in a very detailed chapter to show the possible complications, then a chapter for the multimode treatments and finally a summary of the various techniques are presented in the form of excellent anatomical diagrams.

This very didactic book follows a logical chapter which makes it particularly easy to consult. It should be within reach of all the doctors, orthopaedic surgeons, neurosurgeons, rheumatologists, specialists in physical therapy and even general practitioners who are brought to practice vertebral infiltrations.

No funds were received in support of this study.

P. Kehr (四)

SOTEST, Strasbourg, France

e-mail: kehrpier@aol.com 